\title{
Geophysical Research Letters
}

\section{RESEARCH LETTER}

10.1002/2017GL073055

Key Points:

- The crystal structure of Mg-rich phyllosilicates has a strong influence on their frictional strength

- Water distribution in phyllosilicate mineral structure affects frictional behavior

- Pore fluid chemistry directly influences Mg-rich phyllosilicate distribution and fault strength

Supporting Information:

- Supporting Information S1

Correspondence to:

C. Sánchez-Roa,

catasroa@ujaen.es

\section{Citation:}

Sánchez-Roa, C., D. R. Faulkner, C. Boulton, J. Jimenez-Millan, and F. Nieto (2017), How phyllosilicate mineral structure affects fault strength in Mg-rich fault systems, Geophys. Res. Lett., 44, 5457-5467, doi:10.1002/ 2017 GL073055.

Received 12 FEB 2017 Accepted 24 MAY 2017 Accepted article online 30 May 2017 Published online 12 JUN 2017

\section{How phyllosilicate mineral structure affects fault strength in Mg-rich fault systems}

\author{
C. Sánchez-Roa' ${ }^{1}$, D. R. Faulkner ${ }^{2}$, C. Boulton ${ }^{2}$ (D) J. Jimenez-Millan ${ }^{1}$, and F. Nieto ${ }^{3}$ (iD \\ ${ }^{1}$ Departamento de Geología y CEACTierra, Unidad Asociada IACT (CSIC-UGR), Universidad de Jaén, Jaén, Spain, ${ }^{2}$ Rock \\ Deformation Laboratory, Department of Earth and Ocean Sciences, University of Liverpool, Liverpool, UK, ${ }^{3}$ Departamento \\ de Mineralogía y Petrología e IACT (CSIC-UGR), Facultad de Ciencias, Universidad de Granada, Granada, Spain
}

\section{Introduction}

Clay minerals are commonly significant components of fault gouges and have been found to play a significant role in controlling fault strength by facilitating shear localization in the weak clay matrix [Shimamoto and Logan, 1981; Tembe et al., 2010]. Consequently, many studies have focused on determining what factors control clay mineral frictional strength [Morrow et al., 2000; Moore and Lockner, 2004; Behnsen and Faulkner, 2012; Sakuma and Suehara, 2015], which is typically much lower than the Byerlee friction range $(0.6 \leq \mu \leq 0.85)$ [Byerlee, 1978]. Several experimental studies have shown that the dominant microphysical processes operating during phyllosilicate deformation include rotation, delamination, and grain fracturing (involving breakage of bonds) during shear [lbanez and Kronenberg, 1993; Mares and Kronenberg, 1993; French et al., 2015]. Many factors influence these processes, including normal stress, grain shape, and grain strength (due to mineralogy) [Guo and Morgan, 2006]. In particular, strength is greatly affected by two factors: lubrication and adhesion [Moore and Lockner, 2004; Sakuma and Suehara, 2015]. Lubrication refers to the lubricating effect of adsorbed water (water molecules held on the mineral surfaces by electrochemical forces). Adhesion occurs within the interlayer space between phyllosilicate structural sheets, which are bonded by electrostatic forces, and may also have interlayer water molecules bonded via hydrogen bonds. Because it directly controls atomic arrangement, mineral crystallographic structure influences the atomic forces and interactions that can contribute to both lubrication and adhesion. Thus, identifying crystallographic controls on minerals present in fault zones can contribute to understanding fault strength.

Mg-bearing phyllosilicates have long been suggested to be implicated in lowering the strength of active faults [Irwin and Barnes, 1975; Reinen et al., 1991; Wintsch et al., 1995; Lockner et al., 2011]. Fault zones enriched in magnesium (Mg) occur in the continental and oceanic crust. Mg enrichment promotes the formation of Mg-rich phyllosilicates within fault rocks including chlorite, talc, serpentine group minerals, fibrous clay minerals (sepiolite and palygorskite), and Mg-rich smectites (i.e., saponite). Previous work on Mg-phyllosilicates under water-saturated conditions has shown very low friction coefficients, $\mu=0.05$ for saponite [Lockner et al., 2011] and $\mu=0.16$ for talc [Escartín et al., 2008; Moore and Lockner, 2008]. As a result of their low strength, the planar phyllosilicate minerals saponite and talc are thought to promote significant weakening and strain localization in various settings, including the oceanic lithosphere and the subduction interface [Moore and Lockner, 2008]. The frictional strength of serpentine minerals has also been investigated [Dengo and Logan, 1981; Reinen et al., 1994; Moore et al., 1996, 1997], with some studies showing significant differences in frictional behavior between minerals with the same chemical composition but different 
crystalline structures (polymorphs) [Reinen et al., 1994]. In contrast to the relatively well studied predominantly platy $\mathrm{Mg}$-phyllosilicates above, the fibrous clay mineral group has not been studied in the context of faulting and friction. Thus, this study concentrates on the behavior of these less studied minerals and compares their frictional properties with their planar equivalents.

Sepiolite and palygorskite constitute a group of Mg-rich phyllosilicates with a fibrous (lath-like) morphology, which is dictated by their crystal structure. The frictional strengths of monomineralic samples of this mineral group have not previously been determined. Sepiolite and palygorskite are Mg-rich phyllosilicates stable up to $325^{\circ} \mathrm{C}$ under hydrothermal conditions [Frank-Kamenetskiy et al., 1969]. They commonly form from reactions involving talc and Mg-rich smectites (i.e., saponite) which are chemically very similar and coexist under the same activity values of $\mathrm{Mg}$ and Si [Birsoy, 2002]. The serpentine group minerals are also associated with the formation of fibrous clay minerals, but they are chemically less similar to the minerals in this study due to their significantly lower Si/Mg chemical ratio [Peters, 1993; Yalçin and Bozkaya, 2004]. Fibrous clay minerals commonly occur in fracture and fault zones [Post and Crawford, 2007; Sánchez-Roa et al., 2016]. Thus, quantifying the frictional behavior of fibrous clay minerals constrains their contribution to the strength of Mg-rich fault gouges and facilitates comparison of the strength of chemically similar but structurally different minerals.

In this study, the results of friction experiments on planar and fibrous Mg-phyllosilicates at nucleation velocities $(0.3$ to $3 \mu \mathrm{m} / \mathrm{s})$ are used to investigate the possible effects of crystal structure on the frictional strength and stability of chemically similar and structurally different minerals. A comparison between water- and argon-saturated experiments is used to explore the role water plays in their frictional behavior. Finally, we present the thermodynamic controls on the distribution of these Mg-rich phyllosilicates in fault zones to describe the implications of the results on fault strength.

\section{Materials and Methods}

The materials selected for the study are palygorskite (PIF-1) (79\% purity) [Chipera and Bish, 2001], sepiolite (SV) (91\% purity) [Viseras et al., 1999], saponite (78\% purity) [Boulton et al., 2017], and talc item 468003 from Ward's Scientific. All samples were sieved to obtain the $<53 \mu \mathrm{m}$ fraction, with the exception of the saponite sample in which the $<2 \mu \mathrm{m}$ separate was obtained. For more details on the selected materials see the supporting information (Figure S1). The main phyllosilicate in each of the samples constitutes more than $75 \%$ of the tested gouge; thus, they are expected to control the bulk frictional properties. However, to some extent, sample impurities could affect sample strength and their contributions cannot be fully disregarded. In particular, the palygorskite gouge contains $\sim 11 \%$ smectite; hence, our measurements may present a lower bound on the strength for this phase.

Friction tests were carried out using a triaxial deformation apparatus with a servo-controlled axial loading system and fluid pressure pump [Faulkner and Armitage, 2013]. Frictional sliding experiments were conducted on $1.5 \mathrm{~mm}$ thick gouge layers using a direct shear sample assembly and methods documented in SánchezRoa et al. [2016]. For more details on experimental methods see the supporting information (Figure S2).

For the argon tests, the pore pressure lines were connected to a vacuum pump to ensure that water (including air humidity) was removed from the system. The samples were kept in a vacuum oven at $80^{\circ} \mathrm{C}$ overnight to ensure complete evaporation of the ethanol used during sample preparation and introduced in the pressure vessel while warm to limit adsorption of water. The use of water as pore fluid during the experiments more closely resembles the conditions found in natural faults, while the use of argon gas as pore fluid is designed to understand the mechanisms of friction and identify the effects on the frictional behavior caused by the physicochemical interactions between water and each of the phyllosilicates studied.

The initial sliding velocity for the $1.5 \mathrm{~mm}$ displacement run-in was $0.3 \mu \mathrm{m} / \mathrm{s}$. A low loading rate was chosen specifically to avoid the development of pore fluid effects, such as overpressure development due to a combination of compaction and low hydraulic diffusivity that could influence the measured strength. The starting permeability was $\sim 10^{-19} \mathrm{~m}^{2}$, reducing to $\sim 10^{-20} \mathrm{~m}^{2}$ during shear. Permeability measurements were conducted using the pore pressure oscillation technique [Fischer, 1992] and processed following the methods in Faulkner and Rutter [2000]. For details on the permeability measurements, see the supporting information (Figure S2). The values of normal stress and fluid pressure were set at $\sigma_{n}=100 \mathrm{MPa}$ and $P_{p}=5 \mathrm{MPa}$ for all 


\section{a}

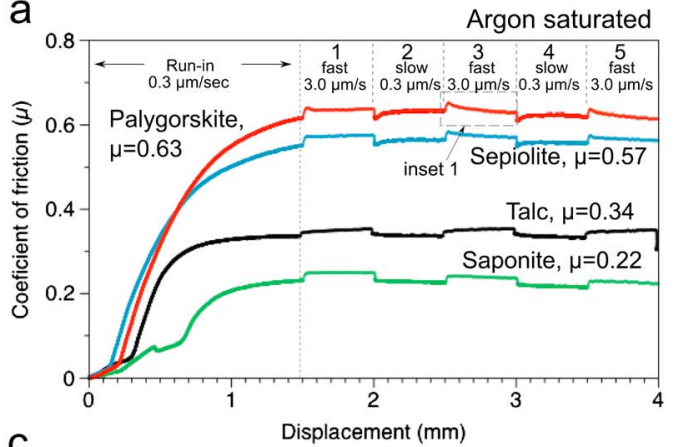

Argon saturated

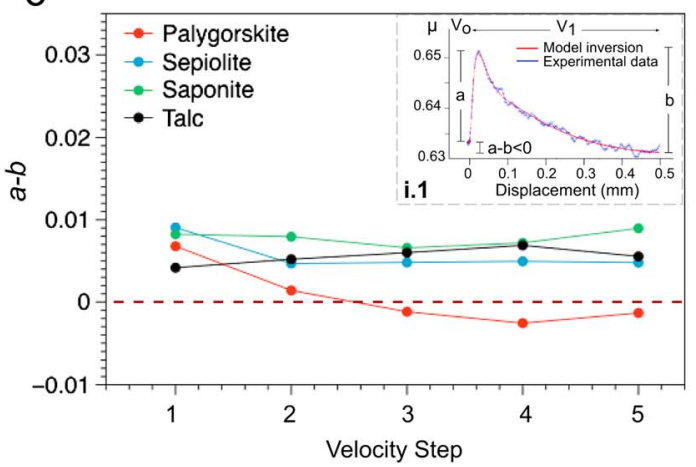

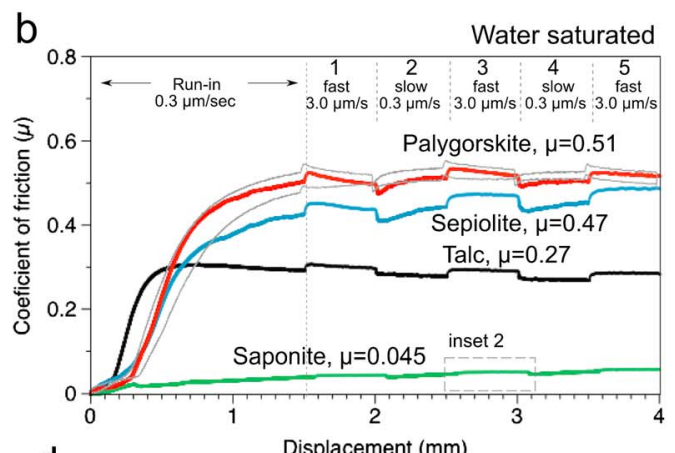

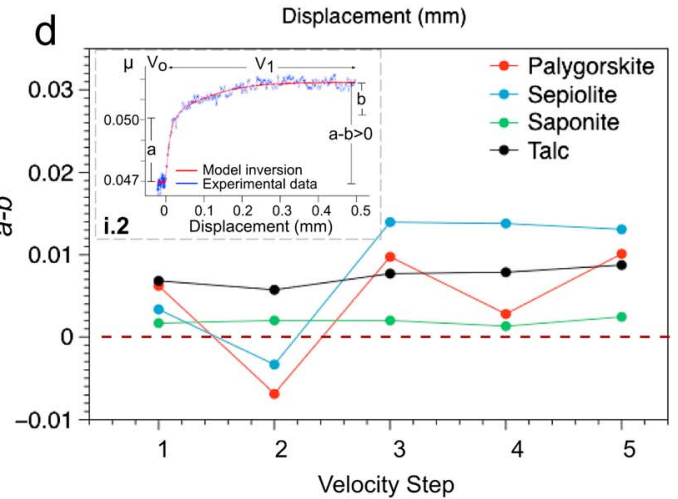

Figure 1. Experimental quantification of the frictional properties of palygorskite, sepiolite, talc, and saponite under (a) argon and (b) water-saturated conditions. The steps within the curves correspond to alternating changes in sliding velocity of 1 order of magnitude ( 0.3 to $3 \mu \mathrm{m} / \mathrm{s}$ ). (c and d) Gray curves on palygorskite water-saturated run plot are duplicate experiments. Values of the friction stability parameter $(a-b)$ for positive and negative velocity steps under argon-saturated (Figure 1c) and water-saturated (Figure 1d) conditions. Inset: enlargement of two individual positive velocity steps at $2.5 \mathrm{~mm}$ of axial displacement from inset 1: Palygorskite under argon conditions and inset 2: saponite under water-saturated conditions. The insets illustrate the model inversion fitting of the experimental data with the aging law and the resulting values of $a, b$, and $a-b$.

experiments. After the run-in, sliding velocity steps were imposed every $0.5 \mathrm{~mm}(0.3-3.0-0.3 \mu \mathrm{m} / \mathrm{s})$ to a total displacement of $4 \mathrm{~mm}$.

Friction coefficient values $(\mu)$ were calculated for each experiment as the ratio of shear stress $(\tau)$ and effective normal stress $\left(\sigma_{n}\right)=$ normal stress $\left(\sigma_{n}\right)$ - pore fluid pressure $\left(P_{p}\right) ;\left(\mu=\tau / \sigma_{n}-P_{p}\right)$. The "true shear stress" was calculated as the force $(F)$ per unit area $(A) ; \tau=F / A$. The area was calculated based on the initial dimensions of the assembly's sliders, which increases in the direction of shearing during displacement $(\tau=F /$ width (length + displacement)). Fitting of the velocity steps using the rate and state formulation with the aging law [Dieterich, 1979] was conducted for all samples through a least squares numerical fitting routine including apparatus stiffness [Noda and Shimamoto, 2009], with the aim of finding the friction rate parameter $(a-b)$, which describes the stability of the sliding surface [Scholz, 1998]. For a description of the methods used in the modeling, see supporting information Text S1.

Scanning electron microscope (SEM) observations were made on polished impregnated samples using a Merlin Carl Zeiss SEM in backscattered electron (BSE) mode and secondary electron (SE) mode. Transmission electron microscope (TEM) images on individual particles were obtained with a Philips CM20 (STEM) microscope operated at $200 \mathrm{kV}$.

\section{Results}

Results of friction experiments on samples of palygorskite, sepiolite, saponite, and talc at $95 \mathrm{MPa}$ effective normal stress, $5 \mathrm{MPa}$ pore pressure, and $25^{\circ} \mathrm{C}$ are presented in Figures $1 \mathrm{a}$ and $1 \mathrm{~b}$. Test reproducibility was good with differences in $\mu<0.05$ for duplicate experiments. Differences between duplicates are much 


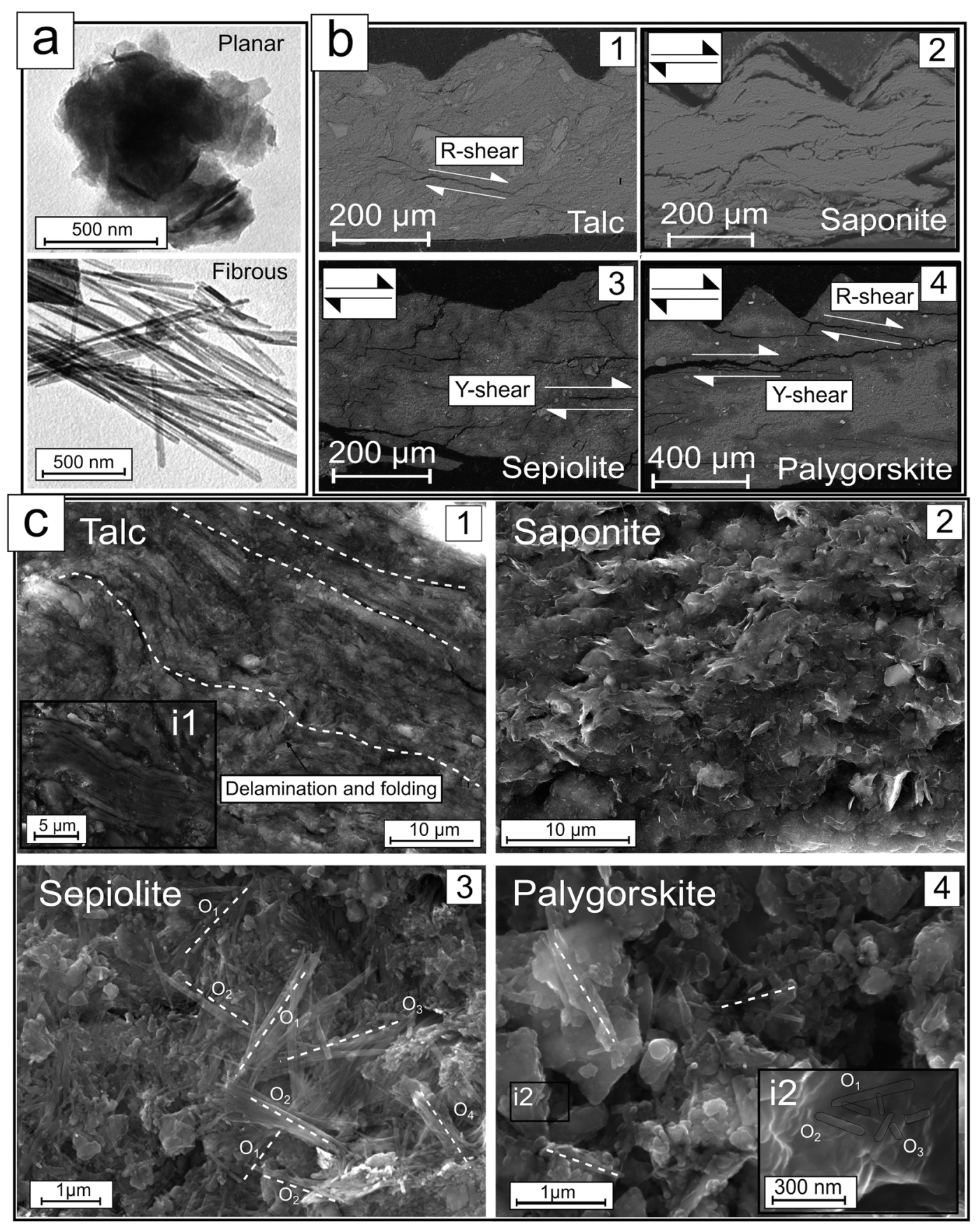

Figure 2. (a) TEM images illustrating the planar morphology (smectite) and fibrous morphology (sepiolite) of the minerals studied. (b) Microstructural comparison of planar and fibrous phyllosilicate gouges recovered at the end of the experiments. BSE images showing poorly developed $Y$ shears and $R$ shears for 1: talc, 2: saponite, 3: sepiolite, and 4: palygorskite. (c) SEM images of the deformed gouges were taken with a combination of in-lens secondary electrons detector (66\%) and secondary electrons detector (33\%). White dashed lines indicate the general orientation of the crystals. 1: SEM image of talc gouge showing an interconnected network of talc crystals oriented on their basal planes with signs of delamination and folding. Inset 1: Folded talc crystal. 2: Saponite crystals oriented on their basal planes. 3: SEM image of sepiolite gouge showing the needle-like morphology of the crystals and the representative microstructure with multiple orientations of the acicular crystals after shearing $\left(\mathrm{O}_{1}, \mathrm{O}_{2}, \mathrm{O}_{3}\right.$, etc.). 4: SEM image of the palygorskite gouge. Inset 2: Higher-magnification image showing how the planar-like grains within the palygorskite gouge are aggregates of palygorskite fibers. 
smaller than the relative strengths between the different minerals. The primary source of error between duplicate experiments likely results from sample preparation.

All samples experienced yield during the initial run-in, before the first positive velocity step. For comparison, the representative friction coefficient of each experiment is taken at $2.49 \mathrm{~mm}$ displacement at the end of a slow-sliding velocity segment $(0.3 \mu \mathrm{m} / \mathrm{s})$. Sepiolite shows values of friction coefficient $(\mu)$ of 0.57 with argon and 0.47 for water-saturated experiments, whereas the palygorskite values of $\mu$ are higher, 0.63 with argon and 0.51 for water (Figure 1). Talc $\mu$ values of 0.34 and 0.27 show the smallest difference between argon and water-saturated experiments, respectively. Experiments run on saponite shows considerably lower friction coefficients $(\mu)$ of 0.22 with argon and 0.045 for water-saturated experiments. Saponite under water-saturated conditions also exhibits the largest displacement-hardening effects. For all samples, friction coefficients in water-saturated experiments were lower than in the argon experiments run under the same conditions of effective normal stress and velocity. However, the extent of this effect is variable between the saponite, talc, and the fibrous clay minerals. Saponite exhibited the greatest effect of water on $\mu$, and talc exhibited the smallest water effect.

All samples tested show strong rate dependency of the friction coefficient. Figures $1 \mathrm{c}$ and $1 \mathrm{~d}$ show the results of changes in sliding velocity imposed during the experiments to determine the rate dependence of the strength. Results of the frictional stability parameter $a-b$ for experiments on talc and saponite show a consistent velocity-strengthening behavior for both positive and negative velocity steps (Figures 1c and 1d). Meanwhile, the frictional stability parameter $a-b$ obtained for the fibrous clay minerals palygorskite and sepiolite shows predominantly velocity-strengthening and velocity-neutral behaviors. However, negative values of the $a-b$ parameter can be observed in the first positive velocity steps after yield in the watersaturated experiments, and in the palygorskite experiment with argon as pore fluid, which is the only experiment that shows consistent velocity weakening (Figures 1c and 1d). For more details on the constitutive parameters for the velocity steps see the supporting information (Table S1).

TEM images of the contrasting morphology of the studied planar and fibrous Mg-rich phyllosilicates are presented in Figure 2a. SEM observations on the deformed samples (Figures $2 b$ and $2 c$ ) show a homogeneous matrix with the development of typical clay-bearing fault gouge microstructures [Rutter et al., 1986] including P foliation, poorly developed $R_{1}$ Riedel shears, and shear-parallel $Y$ shears (Figure $2 \mathrm{~b}, 1$ to 4 ). Under higher magnification (Figure 2c) on a cut parallel to the slip direction and perpendicular to the shear plane, different arrangements of the individual crystals were observed. Crystals in the planar phyllosilicates talc and saponite (Figure 2c, 1 and 2) are aligned on their basal planes and appear to show the start of delamination and folding of the grains (Figure 2c, 1 and inset 1). The fibers of sepiolite and palygorskite are not aligned within the shears. Instead, samples appear to show multiple fiber orientations forming a grid-like network visible within the $R_{1}$ Riedel shears (Figure 2c, 3 and 4).

\section{Discussion}

\subsection{Crystallographic Control on the Frictional Strength and Stability}

The results of the experiments performed show significantly higher friction coefficients for the fibrous clay minerals sepiolite and palygorskite than for the planar clay minerals talc and saponite, despite their chemical similarity. The actual differences could be still higher than those shown by the experiments due to the presence of minor impurities of planar minerals in the fibrous samples investigated. Planar phyllosilicates are well known for their perfect (001) cleavage, a consequence of their continuous interlayer spacing between one T-O (one tetrahedral sheet: one octahedral sheet) or T-O-T (two tetrahedral sheets: one octahedral sheet) layer and the next (Figure 3). The lower bonding energy of the adhesive forces that bind the layers together makes the interlayer the most likely place to localize shear deformation. Consequently, the frictional strength of phyllosilicates has previously been compared to the strength of their (001) interlayer bond energy [Moore and Lockner, 2004; Behnsen and Faulkner, 2012].

In the case of fibrous clay minerals, periodic inversions of the apical oxygen atoms in the Si-tetrahedra create discontinuous alumino-magnesic-silicate ribbons, which dictate the fibrous morphology of the minerals. The discontinuous ribbons remain together through Si-O-Si covalent bonds which serve as "bridges" [Yariv, 1986] (Figure 3). The presence of these strong bridges forces the fibrous structures to shift the cleavage planes to 


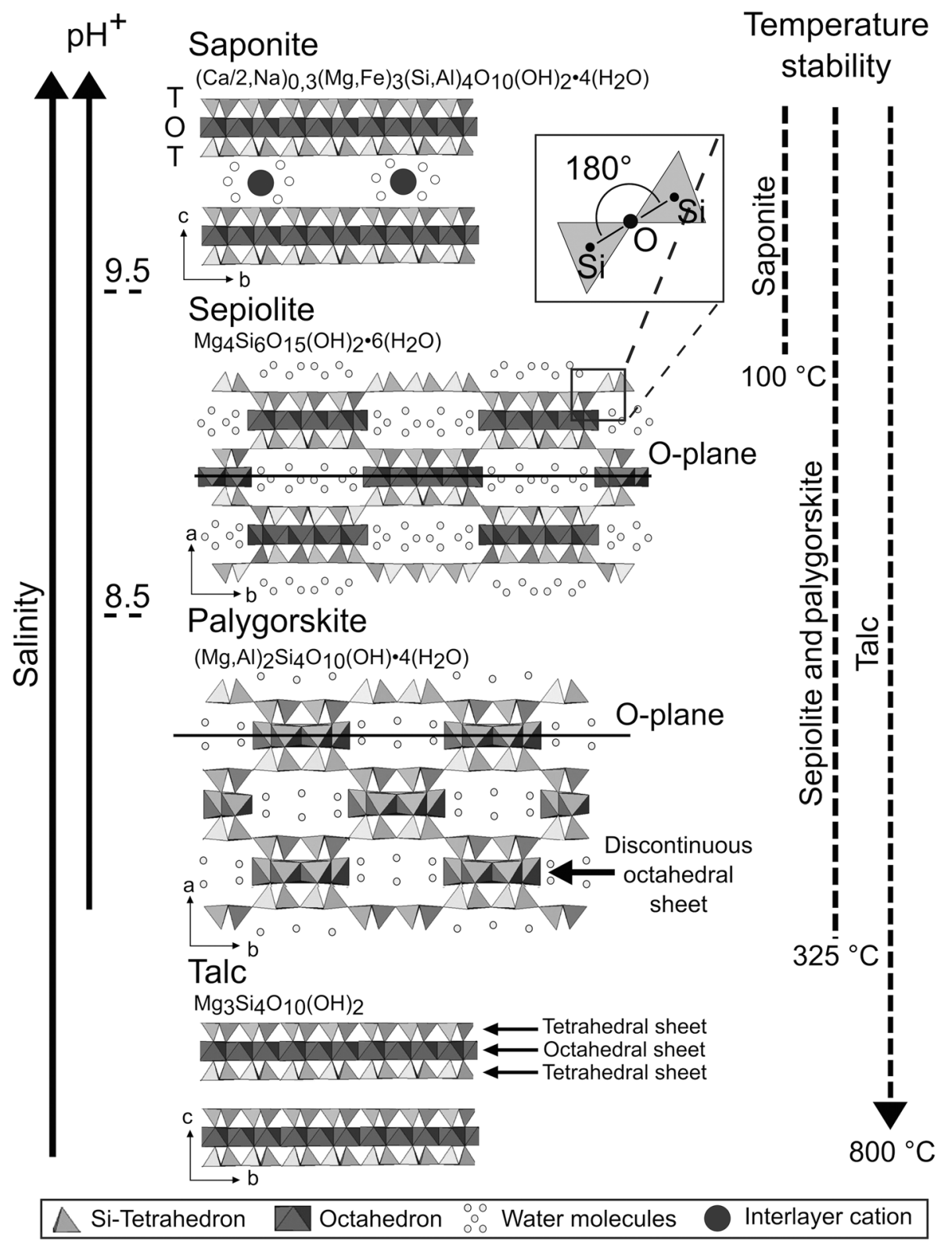

Figure 3. Schematic diagram illustrating the different crystal structures, as well as $\mathrm{pH}+$, salinity, and temperature stability of the Mg-rich phyllosilicate minerals in the study. Mineral structures are after Guggenheim and Krekeler [2011].

the octahedral planes (O planes), where deformation (delamination) must involve the breaking of the ionic bonds of the octahedral layer. The breaking of ionic bonds requires higher shear stresses than those involved in shearing of weakly bonded planar structures in this study and partly explains the difference in frictional strength between these planar and fibrous Mg-rich clay minerals.

This case of crystallographic control can be compared to that of serpentine polymorphs, where experiments at room temperature show higher friction coefficients for the fibrous polymorph antigorite (0.5-0.85) [Reinen et al., 1994] and low friction coefficients for the polymorph chrysotile [Moore et al., 1996]. Antigorite has the same Si-O-Si covalent bridging bonds as palygorskite and sepiolite [Yariv, 1986], which can explain its higher strength. Chrysotile, while also fibrous in morphology due to its tubular structure, does not have periodic inversions or connections between the tubes and therefore lacks the strong Si-O-Si bridging group. This difference in strength for phyllosilicates with fibrous morphologies implies that crystal structure has a stronger influence on the frictional strength than particle morphology. 
With regard to the frictional stability parameter $a-b$, the minerals studied are predominantly velocity strengthening, with sepiolite and palygorskite sometimes exhibiting velocity-neutral or even velocityweakening behavior. Results of the stability parameter $a-b$ for talc agree with results from previous experiments, showing a consistent velocity-strengthening behavior for both positive and negative velocity steps [Moore and Lockner, 2008]. Similarly, our velocity-strengthening results for the saponite gouge agree with stability parameter $a-b$ for a gouge with high saponite content yielding velocity-strengthening results [Moore et al., 2016]. Most of the positive velocity steps (where sliding velocity is increased) for saponite and talc were modeled using negative values of the state parameter $b$; the microphysical basis for the occurrence of negative $b$ can be related to grain-scale contact saturation [Ikari et al., 2009; Smith and Faulkner, 2010], changes in viscosity of the water phase in the contacts [Niemeijer and Collettini, 2013], or transient pore pressure changes [Samuelson et al., 2009]. In contrast, $b$ values for sepiolite and palygorskite were always positive (supporting information Table S1), possibly indicating that the microphysical processes involved in the friction of the fibrous and planar minerals in this study are different or have a different dependence on velocity. The stability parameter $(a-b)$ results for the lowest-displacement positive velocity steps in the water-saturated fibrous clay minerals show velocity-weakening behavior and thus the potential for earthquake nucleation [Scholz, 1998]. However, exploration of a wider range of velocities, temperatures, and normal stresses is required for extrapolation of the data to crustal-scale conditions, which is outside the scope of this study.

\subsection{Strength Results and Effects of Water Distribution}

The results of talc friction experiments using argon as pore fluid $(\mu=0.34)$ are in good agreement with those reported for the dry frictional strength of talc in previous studies $(\mu=0.35-0.36)$ [Moore and Lockner, 2004; Moore and Rymer, 2007]. The results of this study for wet talc ( $\mu=0.27)$ show values slightly higher than previously reported ( $\mu=0.18-0.20$ ) [Moore and Lockner, 2004; Behnsen and Faulkner, 2012], but this small discrepancy is within the experimental variability. Talc exhibits the smallest difference between frictional properties under argon- and water-saturated conditions, whereas all the other minerals tested show a significant reduction in friction with the addition of water (Figure 1). Talc crystal structure has no cation substitutions in either the tetrahedral or octahedral layers resulting in an electrostatically neutral T-O-T structure [Meunier, 2005]. The lack of electrostatic charge prevents water molecules from bonding in the interlayer space (unlike other platy phyllosilicates) and therefore would not be expected to produce any difference in friction coefficient with water or argon as the pore fluid (Figures 1 and 3). Adsorbed water on mineral surfaces might be expected to produce a difference in frictional behavior, but talc can only adsorb one monolayer of water to its surface [Wang et al., 2006]. However, removal of this monolayer of water may be the primary factor responsible for the small difference in friction coefficients measured during the argon- and watersaturated experiments.

The results of saponite friction coefficient using argon as pore fluid $(\mu=0.22)$ are lower than those reported for the dry frictional strength of montmorillonite in previous studies, which range from $\mu=0.39$ to $\mu=0.8$ [Moore and Lockner, 2007; Behnsen and Faulkner, 2012]. However, a direct comparison cannot be drawn given that all reported friction experiments on saponite have been conducted using water as pore fluid. Meanwhile, the results of this study for wet saponite $(\mu=0.045)$ show very good agreement with the values reported for a highly pure saponite sample $(\mu=0.05)$ [Lockner et al., 2011]. The planar phyllosilicate saponite shows the largest difference between water-saturated and argon-saturated friction coefficients in this study (Figure 1). For phyllosilicates such as smectites, substitutions in the tetrahedral layers (common in saponite, where $\mathrm{Si}^{4+}$ is replaced by $\mathrm{Al}^{3+}$ ) and substitutions in the octahedral layers result in a deficit of positive charge in the structure, leading to the need for interlayer cations to balance the excess of negative charges. The cations within the interlayer space have the ability to hydrate [Norrish, 1954], resulting in continuous sheets of hydrogen-bonded water molecules that decrease tetrahedral layer contact area and reduce shear strength [Schleicher et al., 2013; Behnsen and Faulkner, 2013]. Furthermore, smectites can adsorb multiple (two to six) monolayers of water to their surface [Clausen et al., 2009]. Thus, the effect of water in smectite friction is strongly related both to adsorbed water on the mineral surface [Moore and Lockner, 2004] and to bound water in the interlayer.

The fibrous clay minerals show a difference between their water-saturated and argon-saturated friction coefficients of around 0.1, a value between that for talc and saponite. Water distribution in fibrous clay minerals differs from the planar phyllosilicates. Due to their crystallographic structure, and the discontinuity of the 
octahedral sheet, the interlayer space in these fibrous minerals is made of channels parallel to the $c$ axis of the fiber [García-Romero and Suárez, 2013]. Two water molecules bond to the edges of the discontinuous octahedral sheets to complete the octahedral coordination of the $\mathrm{Mg}$ atoms. In addition, nonstructurally bound water occurs within the channels. This interlayer water may affect fibrous mineral friction by decreasing direct contact between surfaces, thus decreasing their friction coefficient under water-saturated conditions (Figure 3). Adsorbed water may play a less significant role in the friction of fibrous phyllosilicates. Unlike talc and smectite surfaces, which can adsorb one or multiple (two to six) monolayers of water respectively, sepiolite has a $3 \AA$ void space on the basal plane that repels the adsorption of water molecules directly on the sepiolite surface due to the absence of hydrogen bonding sites in the hydrophobic basal plane [Benli et al., 2012]. Thus, the interlayer water (water in the channels, both bound and unbound) likely influences the friction of fibrous clay minerals more than adsorbed water.

The observed differences in the strength, stability, and microstructures of fibrous and planar clay minerals indicate that gouge microstructures influence the deformation mechanisms operating during frictional sliding. In particular, the stronger fibrous clays are influenced by the observed lack of fiber alignment that result in the grid-like microfabric seen in electron microscope images (Figure 2c, 3 and 4). This microfabric can be related to the exposed crystal surfaces of the fibrous minerals, which have numerous atomic-scale barriers; these barriers create rough surfaces that resist alignment and exhibit relatively high frictional strength. Fibrous phyllosilicates have specific surface areas that vary from 95 to $400 \mathrm{~m}^{2} / \mathrm{g}$ for sepiolite [Hibino et al., 1995] and $173 \mathrm{~m}^{2} / \mathrm{g}$ for palygorskite [Dogan et al., 2006]. These surface areas are considerably larger than those of the planar phyllosilicates in this study, around $65.2 \mathrm{~m}^{2} / \mathrm{g}$ for smectites [Dogan et al., 2006] and $7.4 \mathrm{~m}^{2} / \mathrm{g}$ for talc [Huang and Fuerstenau, 2001]. A combination of a strong mineral structure, high contact area, and a grid-like microfabric explain the higher friction coefficients found for fibrous clay minerals compared to their planar equivalents.

\subsection{Thermodynamic Controls on the Distribution of Mg-Rich Phyllosilicates}

Given the marked difference between the frictional properties of planar and fibrous Mg-phyllosilicates, the thermodynamic stability and conditions necessary for transformation from one mineral group to another in natural faults become a key question. In terms of thermodynamic stability, smectite minerals as pure phases are restricted to the upper $3-4 \mathrm{~km}$ and are generally unstable at temperatures $>100^{\circ} \mathrm{C}$, when the smectite transformation to illite-smectite and chlorite-smectite mixed layered minerals is noticeable [Inoue and Utada, 1991; Vazquez et al., 2016]. Sepiolite and palygorskite are stable to higher temperatures $\left(\sim 325^{\circ}\right.$ C) than smectites and break down to talc and quartz at these high temperatures independent of pressure conditions [Frank-Kamenetskiy et al., 1969]. Talc is the most stable Mg-rich phyllosilicate over a wide range of temperature-pressure conditions ranging from surficial environments to temperatures of $\sim 800^{\circ} \mathrm{C}$ and pressures of 1-2 GPa [Moore and Lockner, 2008].

Talc, saponite, sepiolite, and palygorskite are chemically similar minerals that occupy the same equilibrium field on Mg-Si activity diagrams [Birsoy, 2002]. Their formation and stability relate primarily to Al activity, changes in $\mathrm{pH}^{+}$, salinity of the water, and reaction kinetics. Chemical stability studies on sepiolite and palygorskite indicate that their occurrence is mainly dictated by $\mathrm{pH}^{+}$and temperature [Guggenheim and Krekeler, 2011]. A high ( $\mathrm{Mg}+\mathrm{Si}) / \mathrm{Al}$ ratio, $\mathrm{pH}^{+}$between 8 to 9.5 , and moderate salinity favor precipitation of fibrous clay minerals instead of the Mg-rich smectites (saponite and stevensite), which are favored by a $\mathrm{pH}^{+}$higher than 9.5 and high-salinity waters [Jones and Galán, 1988].

Transformations between fibrous and planar phyllosilicates are likely important processes that affect fault strength and stability. Natural cases of this transformation include epitaxial overgrowth of smectite on palygorskite [Krekeler et al., 2005]. Meanwhile, experimental studies exploring transformation of palygorskite and sepiolite to smectites (at conditions found in shallow, brittle portions of fault zones) have obtained welldeveloped transformation reactions at $T=22$ to $180^{\circ} \mathrm{C}$, pressures $P=$ atmospheric pressure to $30 \mathrm{MPa}$, and $\mathrm{pH}=6$ to 12 [Golden et al., 1985; Wang et al., 2015]. Once again, pore fluid chemistry is the most important factor controlling the transformation.

The scarcity of fibrous clay minerals in surface fault rock outcrops does not rule out their stability and abundance in depth. Evidence of sepiolite and palygorskite transformation to smectites as a result of fluid-rock interaction in surface outcrops indicates that they could exist widely in their fibrous configuration at 
seismogenic depths [Callen, 1984; Krekeler et al., 2005]. Sepiolite and palygorskite have been observed in cores recovered from the Mariana fore-arc region [Natland and Mahoney, 1982], and minor amounts of palygorskite were recognized in cores recovered from the San Andreas Fault [Bradbury et al., 2011, 2015], demonstrating that fibrous clay minerals can indeed constitute important amounts of fault gouges in Mg-rich fault systems and influence frictional sliding at seismogenic depths.

\section{Concluding Remarks}

The distribution of chemically similar Mg-rich phyllosilicates can significantly influence fault strength depending on the abundance of either weak platy minerals ( $\mu=0.045-0.22)$ or stronger fibrous clay minerals ( $\mu=0.44-0.63$ ) (Figure 1). This strength variation may also be accompanied by a transition in the stability regime of crustal faults, which can vary from a velocity-strengthening, stable regime when planar phyllosilicates are present to a velocity-neutral regime when fibrous clay minerals dominate (Figure 1). Subtle changes in pore fluid chemistry within fault zones control the formation of Mg-rich mineral phases with markedly different crystallographic structures and frictional behaviors.

\section{Acknowledgments}

The authors thank H. Noda for his code used in the numerical fitting of the experimental data. We thank T. Tesei, two anonymous reviews, and Associate Editor Ake Fagereng for their comments that led to significant improvements. Diane Moore is thanked for valuable comments on a previous version of this manuscript. This work was supported by MINECO research projects CGL201130153-C02-01 and CGL2011-30153-C0202, Universidad-Caja Rural de Jaén research projects UJA2014/06/17 and UJA2015/07/10, Junta de Andalucía Research Groups RNM-179 and RNM325, UK NERC grant NE/J024449/1, and Spanish Ministerio de Economía y Competitividad F.P.I. grant BES-2012052-562. All data sets used in this study are presented in this paper and in the supporting information file.

\section{References}

Behnsen, J., and D. R. Faulkner (2012), The effect of mineralogy and effective normal stress on frictional strength of sheet silicates, J. Struct. Geol., 42, 49-61, doi:10.1016/j.jsg.2012.06.015.

Behnsen, J., and D. R. Faulkner (2013), Permeability and frictional strength of cation-exchanged montmorillonite, J. Geophys. Res. Solid Earth 118, 2788-2798. doi:10.1002/jgrb.50226.

Benli, B., H. Du, and M. S. Celik (2012), The anisotropic characteristics of natural fibrous sepiolite as revealed by contact angle, surface free energy, AFM and molecular dynamics simulation, Colloids Surfaces A Physicochem. Eng. Asp., 408, 22-31, doi:10.1016/ j.colsurfa.2012.04.018.

Birsoy, R. (2002), Formation of sepiolite-palygorskite and related minerals from solution, Clays Clay Miner., 50(6), 736-745, doi:10.1346/ 000986002762090263.

Boulton, C. J., C. D. Menzies, V. G. Toy, J. Townend, and R. Sutherland (2017), Geochemical and microstructural evidence for interseismic changes in fault zone permeability and strength, Alpine Fault, New Zealand, Geochem. Geophys. Geosyst., 18, 238-265, doi:10.1002/ 2016 GC006588.

Bradbury, K. K., J. P. Evans, J. S. Chester, F. M. Chester, and D. L. Kirschner (2011), Lithology and internal structure of the San Andreas Fault at depth based on characterization of Phase 3 whole-rock core in the San Andreas Fault Observatory at Depth (SAFOD ) borehole, Earth Planet. Sci. Lett., 310(1-2), 131-144, doi:10.1016/j.epsl.2011.07.020.

Bradbury, K. K., C. R. Davis, J. W. Shervais, S. U. Janecke, and J. P. Evans (2015), Composition, alteration, and texture of fault-related rocks from Safod core and surface outcrop analogs: Evidence for deformation processes and fluid-rock interactions, Pure Appl. Geophys., 172(5), 1053-1078, doi:10.1007/s00024-014-0896-6.

Byerlee, J. (1978), Friction of rocks, Pure Appl. Geophys., 116(4-5), 615-626, doi:10.1007/BF00876528.

Callen, R. A. (1984), Clays of the palygorskite-sepiolite group: Depositional environment, age and distribution, in Developments in Sedimentology, vol. 37, edited by A. Singer and E. Galan, pp. 1-37, Elsevier, Amsterdam.

Chipera, S. J., and D. L. Bish (2001), Baseline studies of the clay minerals society source clays: Powder X-ray diffraction analyses, Clays Clay Miner., 49(5), 398-409, doi:10.1346/CCMN.2001.0490511.

Clausen, P., W. Andreoni, A. Curioni, E. Hughes, and C. J. G. Plummer (2009), Water adsorption at a sodium smectite clay surface: An ab initio study of the first stage, J. Phys. Chem. C, 113(34), 15,218-15,225, doi:10.1021/jp901162s.

Dengo, C. A., and J. M. Logan (1981), Implications of the mechanical and frictional behavior of serpentinite to seismogenic faulting, J. Geophys. Res., 86, 10,771-10,782, doi:10.1029/JB086iB11p10771.

Dieterich, J. H. (1979), Modeling of rock friction: 1. Experimental results and constitutive equations, J. Geophys. Res., 84, 2161-2168, doi:10.1029/JB084iB05p02161.

Dogan, A. U., M. Dogan, M. Onal, Y. Sarikaya, A. Aburub, and D. E. Wurster (2006), Baseline studies of the clay minerals society source clays: Specific surface area by the BET method, Clays Clay Miner., 54(1), 62-66, doi:10.1346/CCMN.2006.0540108.

Escartín, J., M. Andreani, G. Hirth, and B. Evans (2008), Relationships between the microstructural evolution and the rheology of talc at elevated pressures and temperatures, Earth Planet. Sci. Lett., 268(3-4), 463-475, doi:10.1016/j.epsl.2008.02.004.

Faulkner, D. R., and P. J. Armitage (2013), The effect of tectonic environment on permeability development around faults and in the brittle crust, Earth Planet. Sci. Lett., 375, 71-77, doi:10.1016/j.epsl.2013.05.006.

Faulkner, D. R., and E. H. Rutter (2000), Comparisons of water and argon permeability in natural clay-bearing fault gouge under high pressure at $20^{\circ} \mathrm{C}$, J. Geophys. Res., 105, 16,415-16,426, doi:10.1029/2000JB900134.

Fischer, G. J. (1992), The determination of permeability and storage capacity: Pore pressure oscillation method. BT—Fault mechanics and transport properties of rocks, Fault Mech. Transp. Prop. Rocks, (8), 1-13.

Frank-Kamenetskiy, V. A., N. V. Kotov, and G. N. Klochkova (1969), Phase transformations in sepiolite and palygorskite at different pressures under hydrothermal conditions, Geokhimiya, 1, 14-21.

French, M. E., F. M. Chester, and J. S. Chester (2015), Micromechanisms of creep in clay-rich gouge from the Central Deforming Zone of the San Andreas Fault, J. Geophys. Res. Solid Earth, 120, 827-849, doi:10.1002/2014JB011496.

García-Romero, E., and M. Suárez (2013), Sepiolite-palygorskite: Textural study and genetic considerations, Appl. Clay Sci., doi:10.1016/ j.clay.2013.09.013.

Golden, D. C., J. B. Dixon, and L. A. Kippenberger (1985), Palygorskite and sepiolite alteration to smectite under alkaline conditions, Clays Clay Miner., 33(1), 44-50.

Guggenheim, S., and M. P. S. Krekeler (2011), The structures and microtextures of the palygorskite-sepiolite group minerals, in Developments in Clay Science, vol. 3, edited by E. Galan and A. Singer, pp. 3-32, Elsevier, Amsterdam. 
Guo, Y., and J. K. Morgan (2006), The frictional and micromechanical effects of grain comminution in fault gouge from distinct element simulations, J. Geophys. Res., 111, B12406, doi:10.1029/2005JB004049.

Hibino, T., A. Tsunashima, A. Yamazaki, and R. Otsuka (1995), Model calculation of sepiolite surface areas, Clays Clay Miner., 43(4), 391-396.

Huang, P., and D. W. Fuerstenau (2001), The effect of the adsorption of lead and cadmium ions on the interfacial behavior of quartz and talc Colloids Surfaces A Physicochem. Eng. Asp, 177, 147-156.

Ibanez, W. D., and A. K. Kronenberg (1993), Experimental deformation of shale: Mechanical properties and microstructural indicators of mechanisms, Int. J. Rock Mech. Min. Sci., 30(7), 723-734, doi:10.1016/0148-9062(93)90014-5.

Ikari, M. J., D. M. Saffer, and C. Marone (2009), Frictional and hydrologic properties of clay-rich fault gouge, J. Geophys. Res., 114, B05409, doi:10.1029/2008JB006089.

Inoue, A., and M. Utada (1991), Smectite-to-chlorite transformation in thermally metamorphosed volcanoclastic rocks in the Kamikita area, northern Honshu, Japan, Am. Mineral., 76(3-4), 628-640, doi:10.1144/GSL.SP.1986.019.01.17.

Irwin, W. P., and I. Barnes (1975), Effect of geologic structure and metamorphic fluids on seismic behavior of the San Andreas Fault system in central and northern California, Geology, 3(12), 713-716, doi:10.1130/0091-7613(1975)3<713:EOGSAM>2.0.CO;2.

Jones, B. F., and E. Galán (1988), Sepiolite and palygorskite, in Hydrous Phyllosilicates (Exclusive Micas), Rev. Mineral., vol. 19, edited by S. W. Bailey, pp. 631-674, Mineral. Soc. of Am., Washington, D. C.

Krekeler, M. P. S., E. Hammerly, J. Rakovan, and S. Guggenheim (2005), Microscopy studies of the palygorskite-to-smectite transformation, Clays Clay Miner., 53(1), 92-99, doi:10.1346/CCMN.2005.0530109.

Lockner, D. A., C. Morrow, D. Moore, and S. Hickman (2011), Low strength of deep San Andreas Fault gouge from SAFOD core, Nature, 472(7341), 82-85, doi:10.1038/nature09927.

Mares, V. M., and A. K. Kronenberg (1993), Experimental deformation of muscovite, J. Struct. Geol., 15(9-10), 1061-1075, doi:10.1016/ 0191-8141(93)90156-5.

Meunier, A. (2005), Clays, pp. 1-57, Springer, Berlin.

Moore, D., and D. A. Lockner (2007), Friction of the smectite clay montmorillonite: A review and interpretation of data, in The Seismogenic Zone of Subduction Thrust Faults, Margins Theor. Exp. Earth Sci. Ser., vol 2, edited by T. H. Dixon and C. Moore, pp. 317-345, Columbia Univ. Press, New York.

Moore, D. E., and D. A. Lockner (2004), Crystallographic controls on the frictional behavior of dry and water-saturated sheet structure minerals, J. Geophys. Res., 109, B03401, doi:10.1029/2003JB002582.

Moore, D. E., and D. A. Lockner (2008), Talc friction in the temperature range $25^{\circ}-400^{\circ} \mathrm{C}$ : Relevance for fault-zone weakening, Tectonophysics, 449(1-4), 120-132, doi:10.1016/j.tecto.2007.11.039.

Moore, D. E., and M. J. Rymer (2007), Talc-bearing serpentinite and the creeping section of the San Andreas Fault, Nature, 448(7155), 795-797, doi:10.1038/nature06064.

Moore, D. E., D. A. Lockner, R. Summers, M. Shengi, and J. D. Byerlee (1996), Strength of crisolite-serpentinite gouge under hydrothermal conditions: Can it explain a weak San Andreas Fault?, Geology, 24(11), 1041-1044, doi:10.1130/0091-7613(1996)024<1041.

Moore, D. E., D. A. Lockner, M. Shengli, R. Summers, and J. D. Byerlee (1997), Strengths of serpentinite gouge at elevated temperatures, J. Geophys. Res., 102, 14,787-14,801, doi:10.1029/97JB00995.

Moore, D. E., D. A. Lockner, and S. Hickman (2016), Hydrothermal frictional strengths of rock and mineral samples relevant to the creeping section of the San Andreas Fault, J. Struct. Geol., 89, 153-167, doi:10.1016/j.jsg.2016.06.005.

Morrow, C. A., D. E. Moore, and D. A. Lockner (2000), The effect of mineral bond strength and absorved water on fault gouge frictional strength, Geophys. Res. Lett., 27, 815-818, doi:10.1029/1999GL008401.

Natland, J. H., and J. J. Mahoney (1982), Alteration in igneous rocks at Deep Sea Drilling Project sites 458 and 459, Mariana fore-arc region: Relationship to basement structure, Initial Rep. Deep Sea Drill. Proj., 60, 769-788, doi:10.2973/dsdp.proc.60.145.1982.

Niemeijer, A. R., and C. Collettini (2013), Frictional properties of a low-angle normal fault under in situ conditions: Thermally-activated velocity weakening, Pure Appl. Geophys., 171(10), 2641-2664, doi:10.1007/s00024-013-0759-6.

Noda, H., and T. Shimamoto (2009), Constitutive properties of clayey fault gouge from the Hanaore fault zone, southwest Japan, J. Geophys. Res., 114, B04409, doi:10.1029/2008JB005683.

Norrish, K. (1954), The swelling of montmorillonite, Discuss. Faraday Soc., 18, 120, doi:10.1039/df9541800120.

Peters, E. K. (1993), D- ${ }^{18}$ O enriched waters of the Coast Range Mountains, northern California: Connate and ore-forming fluids, Geochim. Cosmochim. Acta, 57(5), 1093-1104, doi:10.1016/0016-7037(93)90043-V.

Post, J. L., and S. Crawford (2007), Varied forms of palygorskite and sepiolite from different geologic systems, Appl. Clay Sci., 36(4), 232-244, doi:10.1016/j.clay.2006.10.003.

Reinen, L. A., J. D. Weeks, and T. E. Tullis (1991), The frictional behavior of serpentinite: Implications for aseismic creep on shallow crustal faults, Geophys. Res. Lett., 18, 1921-1924.

Reinen, L. A., J. D. Weeks, and T. E. Tullis (1994), The frictional behavior of lizardite and antigorite serpentinites: Experiments, constitutive models, and implications for natural faults, Pure Appl. Geophys. PAGEOPH, 143(1-3), 317-358, doi:10.1007/BF00874334.

Rutter, E. H., R. H. Maddock, S. H. Hall, and S. H. White (1986), Comparative microstructures of natural and experimentally produced clay-bearing fault gouges, Pure Appl. Geophys., 124(1-2), 3-30, doi:10.1007/BF00875717.

Sakuma, H., and S. Suehara (2015), Interlayer bonding energy of layered minerals: Implication for the relationship with friction coefficient, J. Geophys. Res. Solid Earth, 120, 2212-2219, doi:10.1002/2015JB011900.

Samuelson, J., D. Elsworth, and C. Marone (2009), Shear-induced dilatancy of fluid-saturated faults: Experiment and theory, J. Geophys. Res., 114, B12404, doi:10.1029/2008JB006273.

Sánchez-Roa, C., J. Jiménez-Millán, I. Abad, D. R. Faulkner, F. Nieto, and F. J. García-Tortosa (2016), Fibrous clay mineral authigenesis induced by fluid-rock interaction in the Galera fault zone (Betic Cordillera, SE Spain) and its influence on fault gouge frictional properties, Appl. Clay Sci., doi:10.1016/j.clay.2016.06.023.

Schleicher, A. M., H. Hofmann, and B. A. van der Pluijm (2013), Constraining clay hydration state and its role in active fault systems, Geochem. Geophys. Geosyst., 14, 1039-1052, doi:10.1002/ggge.20077.

Scholz, C. H. (1998), Earthquakes and friction laws, Nature, 391(6662), 37-42, doi:10.1038/34097.

Shimamoto, T., and J. M. Logan (1981), Effects of simulated clay gouges on the sliding behavior of Tennessee sandstone, Tectonophysics, 75 , 243-255.

Smith, S. A. F., and D. R. Faulkner (2010), Laboratory measurements of the frictional properties of the Zuccale low-angle normal fault, Elba Island, Italy, J. Geophys. Res., 115, B02407, doi:10.1029/2008JB006274. 
Tembe, S., D. A. Lockner, and T. F. Wong (2010), Effect of clay content and mineralogy on frictional sliding behavior of simulated gouges: Binary and ternary mixtures of quartz, illite, and montmorillonite, J. Geophys. Res., 115, B03416, doi:10.1029/2009JB006383.

Vazquez, M., B. Bauluz, F. Nieto, and D. Morata (2016), Illitization sequence controlled by temperature in volcanic geothermal systems: The Tinguiririca geothermal field, Andean Cordillera, Central Chile, Appl. Clay Sci., 134, 221-234, doi:10.1016/j.clay.2016.04.011.

Viseras, C., G. H. Meeten, and A. Lopez-Galindo (1999), Pharmaceutical grade phyllosilicate dispersions: The influence of shear history on floc structure, Int. J. Pharm., 182(1), 7-20, doi:10.1016/S0378-5173(99)00075-7.

Wang, J., A. G. Kalinichev, and R. J. Kirkpatrick (2006), Effects of substrate structure and composition on the structure, dynamics, and energetics of water at mineral surfaces: A molecular dynamics modeling study, Geochim. Cosmochim. Acta, 70(3), 562-582, doi:10.1016/ j.gca.2005.10.006.

Wang, W., Z. Zhang, G. Tian, and A. Wang (2015), From nanorods of palygorskite to nanosheets of smectite via a one-step hydrothermal process, RSC Adv., 5, 58,107-58,115, doi:10.1039/C5RA05187H.

Wintsch, R. P., R. Christoffersen, and A. K. Kronenberg (1995), Fluid-rock reaction weakening of fault zones, J. Geophys. Res., 100 , 13,021-13,032, doi:10.1029/94JB02622.

Yalçin, H., and Ö. Bozkaya (2004), Ultramafic-rock-hosted vein sepiolite occurrences in the Ankara ophiolitic mélange, Central Anatolia, Turkey, Clays Clay Miner., 52(2), 227-239, doi:10.1346/CCMN.2004.0520209.

Yariv, S. (1986), Infrared evidence for the occurrence of SiO groups with double-bond character in antigorite, sepiolite and palygorskite, Clay Miner., 21, 925-936. 